Tomislava T. Đorđević Univerzitet u Beogradu Filološki fakultet**
791.44.071.1(460) Алмодо́вар П. https://doi.org/10.18485/analiff.2019.31.2.17

Originalni naučni rad

Primljen: 27.07.2019

Prihvaćen: 18.11 .2019

\title{
DŽULIJET I HULIJETA - KANADSKO ISKUSTVO U ŠPANSKOM KULTURNOM KONTEKSTU
}

Inspirisan pričama Alis Manro, Pedro Almodovar odlučuje da snimi svoj prvi film na engleskom jeziku. Međutim, na putu između ideje i njene realizacije, stajala je, kako se ispostavilo, prepreka u vidu različitosti dva sveta kojima kanadska autorka i španski režiser pripadaju. Almodovar je ovu prepreku premostio smestivši priču o Džulijet u okvire španskog kulturnog konteksta. Kreativnost podstaknuta slobodom koju je osetio vrativši se na u svakom smislu poznato tlo, omogućila mu je da vešto istakne razlike između dve kulture, istovremeno uspešno prenoseći na platno glavna obeležja proze Alis Manro koja su mu upravo i bila nadahnuće za stvaranje.

Ključne reči: tišina, krivica, tragedija, smrt, sećanje, empatija, hispanska kultura, ženska solidarnost

\section{Uvod}

Još u filmu Koža u kojoj živim (La piel que habito, 2011), moglo se primetiti da je Pedro Almodovar ljubitelj priča Alis Manro. Njena zbirka Bekstvo (Runaway, 2004) ${ }^{1}$ pojavljuje se u jednoj od scena, a pet godina kasnije u bioskope stiže i film Hulijeta (Julieta) inspirisan upravo pričama iz ove zbirke.

Film je prvobitno trebalo da se zove Tišina (Silence) i da bude prvo ostvarenje španskog režisera na engleskom jeziku. Pripremajući se za sni-

\footnotetext{
* tomislavadj@gmail.com

** Rad je nastao u okviru doktorskih studija na Filološkom fakultetu u Beogradu na predmetu Ženske studije u anglo-američkoj književnosti, pod mentorstvom prof. dr Aleksandre Jovanović.

1 Prvo izdanje na engleskom jeziku: Munro, A. (2004). Runaway. Toronto: McClelland \& Stewart. Citati u radu navedeni su prema srpskom izdanju - Manro, A. (2015). Bekstvo. Preveo Predrag Šaponja. Zrenjanin: Novi Sad: Agora.
} 
manje, Almodovar odlazi u Kanadu, ali doživljava neku vrstu kulturološkog šoka i odlučuje da radnju filma ipak smesti malo južnije, u Sjedinjene Američke Države. Kako ovaj pokušaj ublažavanja razlika s kojima se suočio nije dao željene rezultate, Almodovar u potpunosti odustaje od ideje da snima na severnoameričkom kontinentu i donosi odluku da se vrati Španiji, španskom jeziku i španskim glumcima. Ovo rešenje pokazalo se kao odlično jer su mu podneblje u kome je rođen i njegovi običaji oduvek bili neiscrpna inspiracija. Kanadsko sivilo zamenjeno je španskim suncem, šezdesete godine 20. veka postale su osamdesete, a Džulijet, glavna junakinja, Hulijeta.

\section{Priče}

Alis Manro ne idealizije stvarnost već je prikazuje u sirovom i surovom obliku. Njene priče bave se temama kao što su bolest, smrt, ubistvo, samoubistvo, neverstvo, fizičko i mentalno propadanje, okrutnost odraslih, ali i dece. Ona se fokusira na tamne strane ljudske prirode i na nepredvidljivost svakodnevnog života, pružajući nam uvid u nešto što bi se moglo nazvati univerzalnim ljudskim iskustvom. U obraćanju povodom dobijanja Nobelove nagrade za književnost 2013. godine, spisateljica o svojim pričama kaže: „Želim da moje priče dotaknu ljude, nebitno da li su u pitanju muškarci, žene ili deca. Želim [...] da sve o čemu određena priča govori dotakne čitaoca na takav način da posle čitanja oseti da je drugačija osoba." ${ }^{2}$

Njeni likovi, posebno ženski, često život provode u nekoj vrsti zatočeništva, sputani okolnostima, ali i sopstvenim (ne)delanjem, neretko pokušavajući da se distanciraju od sopstvenog života. Iako dane provode u čežnji za begom od klaustrofobične atmosfere svojih zagušljivih života, kada im se i pruži prilika za tako nešto, deluje kao da se svim silama trude da se što pre vrate među te nevidljive, ali dobro poznate zatvorske zidine. Odnosi među likovima su uglavnom hladni, lišeni empatije, i opterećeni mentalitetom učmale provincijske sredine.

Tri priče iz pomenute zbirke Bekstvo - Prilika (Chance), Uskoro (Soon), Tišina (Silence) - prate život Džulijet, nastavnice latinskog, od

2 Alice Munro: In Her Own Words: 2013 Nobel Prize Lecture in absentia, https:/www.nobelprize.org/uploads/2018/06/munro-lecture.pdf 
njenih ranih dvadesetih godina života do zrelog doba. Alis Manro se u velikom broju svojih priča bavi muško-ženskim odnosima, kao i veoma kompleksnim odnosom majki i ćerki, pa tako i u ove tri priče ti odnosi predstavljaju fokus pripovedanja. Džulijet, centralni lik, istovremeno je i majka i ćerka, i ljubavnica i prevarena žena. Vidimo kako se njen odnos prema ljudima i okolnostima menja tokom vremena, isto kao što i njen doživljaj odnosa sa bliskim ljudima, kao i doživljaj stvarnosti trpe promene. Kao što zapaža Adžaj Hebl (Ajay Heble, 1994: 125), „Interpretacija prošlosti se menja kako vreme prolazi“".

Džulijet se od malih nogu nije uklapala u malograđanska shvatanja gradića iz koga je potekla. Ne samo ona, već i njeni roditelji, uvek su odudarali od primitivizma koji je vladao oko njih - načinom života, obrazovanjem, oblačenjem. Džulijet odlazi iz te sredine, ali se prilikom kratkotrajnog povratka suočava sa sopstvenom zabludom - njeni roditelji, kako se ispostavilo, i nisu toliko širokih shvatanja. Oni se stide ćerke koja živi u nevenčanoj zajednici sa čovekom s kojim ima dete, i zbog toga, između ostalog, lažu da voz više ne staje na stanici u njihovom mestu kako ne bi bili viđeni zajedno, a sliku koju im je poklonila za Božić sklanjaju na tavan kao neprikladnu za oči žene koja im pomaže u kući. Otkrivši tu sliku simboličnog naziva Ja i selo na tavanu, Džulijet otkiva i da je slika koju je imala o svojoj porodici, slika koja je postojala, čini se, samo u njenom sećanju. U stvarnosti, od oca, koji joj je bio uzor u detinjstvu i koga je doživljavala kao čoveka modernih shvatanja, dobija ponižavajuća pitanja u vezi sa detetom („Kako se preziva? [...] Znači, dao joj je svoje prezime.“ (Manro, 2015: 73)) i neku vrstu podsmeha, kako zbog privatnog života, tako i zbog profesionalnog neuspeha. Upravo je on, saznajemo, inicijator svih tih skrivanja i podilaženja malograđanskim principima. Za razliku od njega, majka joj je podrška i oslonac, ona ne odobrava postupke svog muža, ali nema pravo glasa, tačnije, njen glas se ne čuje, ne važi. Međutim, Džulijet nije u stanju da joj uzvrati istom merom. Ona sebe uskraćuje majci. Na Sarine reči: „Kada me jako uhvati, kada mi se zaista sloši... znaš li šta tada pomislim? Pomislim, u redu... Pomislim, uskoro... Uskoro ću videti Džulijet.“ (Manro, 2015: 96), Džulijet ostaje potpuno nema. Sara je štiti od očeve zluradosti i naziva je svojom ,predivnom ćerkom“ (Manro, 2015: 91), dok Džulijet deluje kao da u sebi nema ni mrvu ljubavi ni empatije prema teško bolesnoj majci. 
Još kao tinejdžerka, saznajemo, u jednom trenutku, oko svoje četrnaeste godine, Džulijet je prezrela ,prozaične“ aktivnosti koje je dotada upražnjavala s majkom, kao što su sređivanje frizure, šivenje odeće, pričanje ženskih priča, i priklonila se ocu. S njime je vodila razgovore na „ozbiljne“ teme i sklopila prećutni dogovor, neku vrstu saveza koji ne samo da je isključivao majku, već je podrazumevao i veoma snishodljiv i nipodaštavajući odnos prema njoj:

Mrzela je Saru što im podriva ozbiljnost razgovora detinjastim pitanjima $i$ to što je uvek pokušavala da sebe vrati u centar pažnje. Zato je sa Semom morala da priča kasno s međusobnim razumevanjem o kome ni ona ni Sem nisu govorili. Sačekaj da se otarasimo Sare. Privremeno, naravno. Zajedno je s time išlo i upozorenje. Ponašaj se lepo prema Sari. Rizikovala je život da bi te rodila, ne zaboravi to (Manro, 2015: 78-79).

Otac joj šalje duple poruke, praktično manipulišući svojim povlašćenim položajem. S jedne strane je podstiče da gaji prezir prema majci, a sa druge je licemerno podseća na Sarinu bolest.

Iako su se simptomi demencije kod nje javili mnogo kasnije u odnosu na bolest srca, Sara je tretirana kao osoba oštećenih kognitivnih sposobnosti već zbog same činjenice da je fizički bila u određenoj meri onesposobljena. Njen muž, umesto podrške, ne propušta priliku da joj se naruga, da je unizi, prenoseći frustraciju njenom bolešću na ćerku. Džulijet toga postaje svesna tek kao odrasla osoba. To saznanje, međutim, nema skoro nikakav efekat na njen odnos prema majci, odnos usvojen još u detinjstvu - Sara i dalje biva „okrivljena“ za svoju bolest, kao da ju je sama prizvala ne bi li mučila muža i dete.

Džulijet ne samo da fizički liči na oca, već s njim deli (osim prezira prema Sari) upravo one osobine kojih se najviše gnuša - malograđanštinu, licemerje, snobizam. Saznajemo da se Sari nije svidela ideja da se Sem posle karijere nastavnika bavi prodajom povrća, kao što ni Džulijet nije bila oduševljena tom idejom, „[a]li ako je već morala da se opredeli, odabrala je njegovu stranu. Nije htela da sebe predstavi kao snoba. Mada je istina bila da je ona videla sebe - i sebe i Sema i Saru, ali najviše sebe i Sema kao ljude koji su, na svoj način, daleko iznad okoline.“ (Manro, 2015: 73) 
Džulijet se identifikuje s ocem, što je jedna od karakteristika ženskih likova Alis Manro. To ne čudi imajući u vidu da je životna priča same autorke utkana u njen rad, pa često deluje, posebno kada je u pitanju odnos majke i ćerke, kao da Manro pišući svoje priče iznova i iznova priča priču o svojoj majci i sebi, sa svakom novom pričom pokušavajući da završi dijalog koji nema kraja, pa se tako s pravom motiv majke na samrti može opisati kao „proganjajući“33 (Carrington, 1989: 189). Zanimljivo je da je, iako se Manro, kako je sama priznala, identifikovala s ocem, upravo majka imala „najviše uticaja na njenu odluku da postane spisateljica“ (May, 2013: 20). O odnosu s majkom Manro (2013) kaže: „Stidela sam je se, volela sam je, nisam želela da me poistovećuju s njom.“

Lik majke mučenice prikazuje ženu zarobljenu u svom telu, svojoj kući, svojoj porodici. Džulijet je kuću svojih roditelja doživljavala upravo kao zatvor, što je za njenu majku i bio: „Sprat se prostirao preko čitavog prizemlja, sobe su bile visoke, ali su podsećale na ćelije.“ (Manro, 2015: 76) Ovo poređenje sa zatvorom kao da je eho priče Mir u Utrehtu (The Peace of Utrecht), u kojoj ćerka Helen, kako primećuje Ildiko de Pap Karington (1989: 187), ,opisuje svoju majku kao fizički zarobljenu u 'kući od kamena' i psihološki izolovanu od strane ćerki u surovim ulogama zatvorskih čuvara koji joj uskraćuju sažaljenje iz ljubavi za kojim vapi i čezne.“ Karington ovo zapažanje ilustruje sledećom rečenicom iz priče: „Odstranile smo sve emocije u komunikaciji s njom, kao kada biste oduzeli meso zatvoreniku da ga oslabite, dok ne umre." (Carrington, 1989: 187)

Likovi ćerki često imaju potrebu da svoj loš odnos prema majkama pravdaju na razne načine, uglavnom indirektno. Majkama je tipično narušena moć govora, tako da su gubitkom tog najupečatljivijeg obeležja čoveka, svedene na nivo životinje, beslovesnog bića, objekta koji smeta. Ovako dehumanizovane, lakše ih je odbaciti, povrediti, obezvrediti.

Kao što Džulijet uskraćuje sebe majci, kao majka uskraćuje sebe i ćerki, i naposletku biva uskraćena za nju. Penelopa je rođena iz Džulijetine veze s Erikom, ribarom koga upoznaje u vozu. Prilikom upoznavanja, on joj saopštava da kod kuće ima ženu, En, teško povređenu u saobraćajnoj

3 Eng. haunting

4 Carrington navodi citat iz priče Mir u Utrehtu (The Peace of Utrecht) prema verziji objavljenoj u zbirci Dance of the Happy Shades. (1968). New York: McGraw-Hill, p. 199. 
nesreći. Ova informacija ne sprečava Džulijet da se upusti u flert s Erikom, i da nije bilo prepreke u vidu menstrualnog krvarenja, i u nešto više. Kada konačno odlučuje da odgovori na njegov poziv upućen u pismu koje joj je nakon tog susreta poslao, i ode kod njega, ispostavlja se da je En preminula i dan pre Džulijetinog dolaska sahranjena. Erik i Džulijet započinju vezu, odnosno nastavljaju ono što su započeli u vozu. Džulijet u tom trenutku, kao i prilikom prvog susreta, ima razumevanja za Erikove potrebe, ali za njegovo zadovoljavanje potreba dok ona sa jednogodišnjom Penelopom boravi u poseti roditeljima - ne.

Krista, žena sa kojom Erik ima seksualne odnose u Džulijetinom odsustvu, bila je prisutna u njegovom životu i pre nego što se upustio u vezu sa Džulijet. Po dolasku u Erikovu kuću njih dve postaju prijateljice. Kada Džulijet godinama kasnije sazna za prevaru, oseća se povređenom i izdanom, i često se sukobljava s Erikom zbog toga. Posle jedne takve svađe, Erik odlazi u ribolov, a Džulijet se s njim pozdravlja hladno i ljutito, ne znajući da je to njihov poslednji pozdrav. Njihova veza, čiji je početak obeležen samoubistvom čoveka koji je sedeo naspram Džulijet u vozu, biva okončana Erikovom smrću u oluji.

Džulijetin osećaj krivice zbog samoubistva saputnika iz voza sa kojim je samo nekoliko trenutka pre tog čina odbila da komunicira iako je bila svesna da on ne želi ništa više od običnog ćaskanja, kratkog je daha, isto kao i osećaj krivice što majci odgovorom nije pružila utehu, ili što nije imala dovoljno razumevanja za potrebe svoje ćerke. Njeno kajanje ima oblik konstatacije, ona zna da je mogla drugačije da postupi, ali uvek nalazi opravdanje za svoje postupke. Njeno sagledavanje stvari se zapravo svodi na konstatno žongliranje između samoopravdavanja i smooptuživanja.

Džulijet u jednom pismu roditeljima iskazuje želju za time da bude „neranjivi pripovedač“ (Manro, 2015: 53). Na neki način, ona u tome i uspeva. Neranjivost podrazumeva emocionalu distancu, ili nedostatak empatije u Džulijetinom slučaju. Usled nedostatka ljubavi prema bližnjima, ljubavi prema drugom ljudskom biću, ona se i našla u situaciji da bude ostavljena, odbačena kao majka. Njena ćerka nakon boravka u duhovnom utočištu prekida kontakt s njom. Ćerkinu stranu priče, baš kao ni Sarinu, nemamo priliku da čujemo. Saznajemo da je Penelopa donekle preuzela ulogu roditelja, to jest majke posle Erikove smrti, a da je Džulijet to prihvatila zdravo za gotovo. Takođe saznajemo da je u vezama s novim par- 
tnerima zanemarivala ćerkine potrebe, postavljajući sebe i svoje potrebe kao prioritet. Džulijet je očigledno svega toga svesna, i u tome vidi mogući razlog za ćerkino nejavljanje. Od takoreći misterioznog nestanka s početka priče Tišina, kako pripovedanje odmiče, i mi, kao i Džulijet, vidimo da je slika koju o sebi ima kao o požrtvovanoj majci ipak samo slika, ideja, želja, dok je stvarnost umnogome drugačija. Ovaj nesklad između Džulijetine priče i njenih postupaka doživljava vrhunac upravo na samom kraju. Ona nas uporno ubeđuje kako joj je teško da živi ne znajući šta je s Penelopom, ali kada joj se pruža prilika da stupi u kontakt s njom, ona ne želi da napravi prvi korak, pronalazeći razne izgovore za takav čin. Dok s jedne strane pribegava „raznim šašavim trikovima“ (Manro, 2015: 106) prilikom javljanja na telefon ne bi li prizvala zvuk Penelopinog glasa, s druge strane joj je nelagodno da ode do pošte i da sazna odakle je stigla čestitka koju joj je ćerka poslala za sopstveni rođendan ,,jer bi je pitali za razlog, zašto traži tu informaciju“ (Manro, 2015: 104), i „,neko bi je sigurno prepoznao“ (Manro, 2015: 104). Dakle, Džulijet ni u zrelim godinama, posle iscrpne introspekcije i analize svog života do tog trenutka, nije spremna ,da izađe iz sebe“, čak ni zarad ljubavi prema detetu, već radije posvećuje svoje vreme imaginarnim likovima iz antičke priče o majci i izgubljenoj ćerki. Njen život bi se mogao opisati upravo njenim rečima: „Niti sam zlobna, niti sam gruba. A ispala sam baš takva.“ (Manro, 2015: 54) Više puta.

Ovakvi ženski likovi karakteristični su za prozu Alis Manro. Ne može im se pripisati loša namera, ali njihovo (ne)činjenje ima loše posledice, i po njih same i po najbližu okolinu. Njihova preterana okrenutost sebi često im stvara osećaj osujećenosti, promašenosti. Posvećenost isključivo sopstvenim potrebama, bez sluha za potrebe bližnjih često ih čini autsajderima i čini da bilo kakvu mogućnost promene takvog stanja nabolje, pod uslovom da dozvole da ne budu u pravu ili po cenu neprijatnosti, odbace i brzo se vrate u svoju zonu komfora i nastave život birajući liniju manjeg otpora. U skladu s tim, tišina ima veliku ulogu u pričama kanadske spisateljice, tako da nije ni čudo što je Almodovar to prepoznao i poželeo da se i film tako zove. U pričama, baš kao i u filmu, i u životu, neizrečene ili prećutane stvari vrlo lako dovedu do tragedije i do života ispunjenog bolom i patnjom. 


\section{Film}

Naslovi nekih od ranijih filmova Pedra Almodovara - Sve o mojoj majci (Todo sobre mi madre, 1999), Pričaj s njom (Hable con ella, 2002), Vrati se (Volver, 2006), mogli bi da posluže kao kroki filma Hulijeta. Opisujući ga, autor kaže: „Niko ne peva, niko ne priča o filmu, nema humora“ (Romney, 2016), dok novinar Gardijana zapaža da je Almodovar na ovaj film primenio, ,pravilo stroge suzdržanosti - nema komičnih replika, ali nema ni suza, niti prenaglašenih emocija“ (Romney, 2016). Ovaj opis sličan je onome koji Majkl Ravič (Michael Ravitch, 2002: 170) koristi za priče Alis Manro - „nema očajanja, ima sasvim malo gneva. Ona [Manro] takve intenzivne emocije drži na odstojanju. Užasne tragedije se dešavaju, ali uvek iza kulisa." (u Duncan, 2011: 161)

Almodovar vešto uspeva da prenese ovo važno svojstvo priča na film, stavljajući začarani krug ćutanja i prećutkivanja u prvi plan. Likovi na svakom koraku nailaze na posledice namernog ili nehotičnog skrivanja istine, srljajući u tragediju.

Iako je izbegao uobičajene melodramske elemente u vidu pevanja, plesa, prenaglašene sentimentalnosti i euforičnih osećanja, Almodovar se okreće „modernom potomku melodrame“ (Živković, 1992: 447), trileru, čiji elementi uspešno naglašavaju ne samo nemogućnost glavne junakinje da shvati ćerkin odlazak i napuštanje, nego i neprirodnost takvog čina.

„Ako devojka od 18 godina prekine vezu s majkom“, objašnjava režiser, „njena majka bukvalno poludi. Ona nikada neće biti sposobna da ponovo izgradi svoj život čak i ako pokuša, i donekle uspe u tome.“ (Champagne, 2016)

Dok Džulijet u pokušaju da potisne bol zbog Penelopinog nejavljanja postaje poznato TV lice, Hulijeta se, nakon bezuspešnog angažovanja policije i privatnog detektiva, povlači, pronalazi posao koji se radi od kuće, i u krajnoj nemoći počinje da piše Antiji, kako se Penelopa zove u filmu. Almodovarov komentar odnosa majke i ćerke u španskoj kulturi ogleda se u Hulijetinim rečima: „Lažna nada da ću te naći me je proždirala, i na njoj sam izgradila svoj novi život [...] Tvoje odsustvo je u potpunosti ispunilo moj život i uništilo ga." I zaista, pri kraju filma vidimo Hulijetu ne samo u stanju izbezumljenosti i očaja, već i bukvalno, fizički izranavljenu, u modricama. 
U radu koji se bavi uticajem kulturoloških faktora na ličnost, Elizabet Ruiz (2005: 39) ističe da se u hispanskoj kulturi od adolescenata ,ne očekuje pobuna kao u kulturama Zapada, ${ }^{5}$ već se vaspitavaju tako da budu svesni odgovornosti prema svojim porodicama i društvu." Antija, na određeni način, postiže taj Zapadni ideal u kome se podstiče ,što manje oslanjanja na porodicu“ (Ruiz, 2005: 52) i u kome se ,roditelji trude da im se deca odvoje [...] i postanu samostalna“" (Ruiz, 2005: 52), istovremeno poništavajući norme i očekivanja sopstvene kulture, tako da njen postupak ima mnogo veću težinu od Penelopinog i, shodno tome, drastičnije posledice.

U priči Džulijet sebe uskraćuje majci, i biva uskraćena za ćerku. U filmu je Hulijeta zaštitnički nastrojena prema majci, njihov odnos je pun topline i nežnosti. Jedna od najdirljivijih scena je upravo ona u kojoj se Sara usred noći budi (i bukvalno i mentalno) i mazi Hulijetu, a zatim njih dve zajedno gledaju Antiju kako spava. U filmu, dakle, nema hladnog odnosa $\mathrm{Hu}-$ lijete prema majci i samim tim je Antijin nestanak još bolniji, neshvatljiviji.

Osećanje krivice ne samo da izjeda Hulijetu, već je, poput zaraze, kako se ispostavlja, ,inficiralo [i] njenu ćerku“ (Almodóvar, 2016), koja odlaskom u duhovno utočište pokušava da izađe na kraj s osećanjem ljutnje prema majci i osećanjem krivice zbog očeve smrti.

Ističući važnost empatije u hispanskoj kulturi, Ruiz (2005: 37) kaže: „Čovek ne može da oseti ono što drugi oseća ukoliko nije u stanju da izgubi sebe u iskustvu drugoga“. Upravo ovo se, na neki način, dešava Antiji. Njen najstariji sin se udavio u reci i ona tek tada postaje svesna bola koji je svojim namernim nestankom nanela majci. Pišući joj pismo i po prvi put od odlaska navodeći svoju adresu na koverti, ona čini korak ka ponovnom uspostavljanju reda, prirodnog stanja stvari.

U pričama Alis Manro sudbina ženskih likova u velikoj meri zavisi od muškaraca - očeva, muževa, ljubavnika. U filmovima Pedra Almodovara muški likovi su uglavnom bledi, baš kao Samuel, Šoan i Lorenco u Hulijeti. Tu su, a kao da nisu. Njih život nosi, a oni se prepuštaju, bez borbe. Žena je ta koja stvara i oblikuje muškarca, i ,ne samo da daje život, već je jača [od muškarca] jer mora da se bori, vodi, pati i uživa u svemu što život nosi. Samo je sudbina jača od nje“, stav je Almodovara (2016).

5 Za ovu tvrdnju E. Ruiz se poziva na rad Bulcroft, R. A., Carmody, D. C. \& Bulcroft, K. A. (1996). Patterns of parental independence giving to adolescents: Variations by race, age, and gender of child. Journal of Marriage and the Family, 58, 866-883. 
Skulptura muškarca specifičnog izgleda pod nazivom Čovek koji sedi, prisutna je tokom celog filma i ima, između ostalog, kako sam autor ističe (Almodóvar, 2016), ulogu da ukaže na moć žene - muškarac predstavljen skulpturom je malen u odnosu na ruke Ave, žene koja ga oblikuje, stvara, a kao gotova skulptura ide iz ruku jedne žene u ruke druge,"one ga dodaju jedna drugoj“", baš kao što Šoana život nosi od jedne do druge žene.

Ženski univerzum je tema kojoj Almodovar pristupa s puno ljubavi i veštine. On uspeva da do detalja prepozna i na platno prenese karakteristike i nepisana pravila komunikacije među ženama, posebno ženama iz krajeva iz kojih je i sam.

Iako i on i Manro u svojim delima prikazuju život u malom mestu, kod Almodovara je taj život, ma koliko težak, obojen vedrim bojama, čak i kada su žene, koje su nosioci tog života, odevene u crninu. Često je za njegove junakinje izmorene brzim tempom života i svakodnevnim brigama, upravo selo pravo utočište, a mentalitet male sredine izvor okrepljujućeg humora za gledaoce.

U pričama Alis Manro, junakinje, poput Sare i Džulijet, nose crnu odeću radi mode, ${ }^{6}$ nerado se vraćaju u manju sredinu, a i kada se vrate, samo se iznova suočavaju s njenom ograničavajućom prirodom i osećajem teskobe koji u njoj preovlađuje.

Može se reći da ono što svet žena u hispanskoj kulturi čini koherentnim i posebnim jesu svojstva koja Elizabet Ruiz (2005: 35) označava pojmovima uzajamna empatija (mutual empathy) i uzajamno osnaživanje (mutual empowerment). Ona u svom radu, pozivajući se na knjigu Women's growth in connection: Writings from the Stone Center (1991), objašnjava da je uzajamna empatija „dvosmerni proces u kome svaki pojedinac deli ono što oseća kao reakciju na osećanja onog drugog, [...] i da je to ujedno i proces koji omogućava svakom pojedincu da napreduje u razumevanju sopstvenih misli i osećanja“, dok uzajamno osnaživanje nastaje kao posledica uzajamne empatije, i za rezultat ima to da „pojedinac sebe vidi kao deo veće celine [...] i shvata da svi imaju uticaj jedni na druge.“

6 Almodovar se često u intervjuima osvrće na svoj „bes prema crnoj boji“ (Barlow, 2016), odnosno prema tradicionalnom nošenju crnine u znak žalosti u ruralnim sredinama u Španiji. Otuda i njegova fascinacija živim bojama po kojima su njegovi filmovi prepoznatljivi. Međutim, kako često u svojim filmovima prikazuje upravo špansko selo, starije žene u crnini su neizostavni likovi u njegovim delima. 
U intervjuu povodom filma (Friedlander, 2016), Rosi de Palma (Rossy de Palma), jedna od omiljenih Almodovarovih glumica, sažela je ova dva koncepta u jednu reč - sororidad, što bi se moglo prevesti kao ženska solidarnost, u najširem značenju. Zanimljivo je da je upravo lik Marijan (u priči Ejlo), koji de Palma tumači, primer izvitoperenog pokušaja ženske solidarnosti. Ona se jedina ne suzdržava od deljenja informacija, i to čini u krajnje neprikladnim trenucima. Njena iskrenost i otvorenost u kombinaciji sa suzdržanošću onih oko nje, stvara savršeno tlo za tragičan sled događaja.

Priče Alis Manro, prema rečima Džonatana Frenzena (Jonathan Franzen, 2004), ,liče na antičku tragediju u proznoj formi.“ Ovu konstataciju nadopunjuje zapažanje Luiz Frans (Louise France, 2005) da „zapleti priča Alis Manro počivaju na jednom ključnom trenutku posle koga nema povratka nazad“. Upravo ovakvi momenti u pričama korespondiraju s onime što se u tragediji naziva tragičkom krivicom. Prema Aristotelu, tragička krivica ili tragička zabluda jeste ,' 'greška u rasuđivanju', kad junak nehotice izazove nesreću. To nije moralni prekršaj, nego pogrešno rasuđivanje, zabuna, postupak izazvan više junakovim temperamentom nego njegovim moralnim osobinama“ (Živković, 1992: 876). Ova definicija savršeno se uklapa i u triptih o Džulijet.

Međutim, ono što pričama možda nedostaje, ako se vrši poređenje sa klasičnom tragedijom, jeste katarsa, ili „osnovno dejstvo emocionalnog pročišćavanja koje, po Aristotelu, tragedija izaziva u gledaocu [...] Aristotelovo shvatanje katarse predstavlja samo eksplikaciju osnovnog uverenja grčkih tragičara da se mudrost stiče 'učenjem kroz patnju'" (Živković, 1992: 342).

Džulijet ne stiče mudrost kroz patnju, za razliku od Hulijete. Isto važi i za Penelopu i Antiju. ${ }^{7}$ Stoga Vordsvortovo viđenje dejstva katarse na planu lirske poezije opisano kao ,, izazivanje skrušenosti i ljudskosti’ nasuprot lažnoj učenosti i snobizmu“"(Živković, 1992: 343) može biti korisno i kada je u pitanju utvrđivanje razlika između filma i priče.

7 Adriana Ugarte (Arconada, 2016), koja tumači ulogu mlade Hulijete, upravo skreće pažnju na terapeutski efekat filma. 


\section{Zaključak}

Kao što Alis Manro, pročitavši Andersenovu Malu sirenu kao devojčica, nije mogla da se pomiri sa tužnim krajem pa je napisala svoju verziju sa srećnim (Manro, 2013), tako Pedro Almodovar nije mogao da zadrži originalnu verziju priče i dozvoli da odnos između Hulijete i njene ćerke ostane nerazrešen. Kao što Manro piše o onome što poznaje („Kako sam odrastala, tako su priče sve više bile o meni samoj“ (Manro, 2013)), tako i Almodovar u svojim filmovima prikazuje ono što je njemu blisko („Nisam bio siguran u sebe kada sam pokušao da snimim film na engleskom“). ${ }^{8}$ Španske ćerke jednostavno ne napuštaju svoje majke, ne nestaju iz njihovih života na neodređeni period.

I Manro i Almodovar su imali majke koje su obeležile njihove živote i koje su uticale na njihov rad. Režiseru je majka bila inspiracija za likove jakih žena, i često se pojavljivala u njegovim filmovima, dok je majka Alis Manro prisutna u likovima majki u njenim pričama, a odnos između njih dve nešto što nikada neće prestati da bude pokretač za nove priče.

Almodovar često, baš kao i Manro, prikazuje život u malom mestu, bekstva, povratke, poroke,bolest, smrt i nemoć, ali su njegove priče ipak za nijansu toplije i malo vedrijih boja, kao što je i vreme u Španiji blaže od hladnih kanadskih vetrova.

\section{LITERATURA}

Almodóvar, P. (Aug 25, 2016). 10 things about Julieta. [on-line]. Dostupno preko: http://www.latinolife.co.uk/articles/10-things-about-julieta-accordingpedro-almodóvar [12.09.2018]

Arconada, A. (ed.). (Apr 8, 2016). Entrevista a Adriana Ugarte por Julieta. esRadiovideos [video zapis]. Dostupno preko: https://www.youtube.com/ watch?v=QpjvZlfEKf8 [10.08.2018]

Barlow, H. (Aug 26, 2016). Pedro Almodovar is feeling the effects of age. The Irish Examiner. [on-line]. Dostupno preko: https://www.irishexaminer.com/lifestyle/artsfilmtv/pedro-almodovar-is-feeling-the-effects-ofage-417793.html [28.08.2018] 
Bulcroft, R. A., et al. (1996). Patterns of parental independence giving to adolescents: Variations by race, age, and gender of child. Journal of Marriage and the Family, 58, 866-883. In Ruiz, E. (2005). Hispanic Culture and Relational Cultural Theory. Journal of Creativity in Mental Health, Vol.1 (1), $33-55$.

Carrington, I. de Papp. (1989). Controlling the Uncontrollable: The Fiction of Alice Munro. Illinois: Northern Illinois University Press.

Champagne, C. (Dec 26, 2016). Behind the Script: How Pedro Almodóvar Turned Alice Munro Short Stories Into "Julieta". Fast Company. [on-line]. Dostupno preko: https://www.fastcompany.com/3066704/behind-thescript-how-pedro-almodovar-turned-alice-munro-short-stories-into-jul [07.08.2018]

Duncan, I. (2011). Alice Munro's Narrative Art. New York: Palgrave Macmillan. France, L. (Feb 6, 2005). Mistress of all she surveys. The Guardian. [on-line]. Dostupno preko: https://www.theguardian.com/books/2005/feb/06/fiction. features2 [10.08.2018]

Franzen, J. (Nov 14, 2004). "Runaway": Alice's Wonderland, The New York Times. [on-line]. Dostupno preko: https://www.nytimes.com/2004/11/14/books/review/runaway-alices-wonderland.html [21.08.2018]

Friedlander, W. (ed.). (Nov 21, 2016). Conversations with Adriana Ugarte and Rossy de Palma of JULIETA. SAG-AFTRA Foundation [video zapis]. Dostupno preko: https://www.youtube.com/watch?v=pjfPYEn6_5A [05.08.2018]

Heble, A. (1994). The Tumble of Reason: Alice Munro's Discourse of Absence. Toronto, Buffalo, London: University of Toronto Press.

Jordan et al. (1991). Women's growth in connection: Writings from the Stone Center. New York: Guilford Press. In Ruiz, E. (2005). Hispanic Culture and Relational Cultural Theory. Journal of Creativity in Mental Health, Vol.1 (1): 33 - 55

Julieta (2016). Film. Režija: Pedro Almodóvar.

Julieta - Press Conference - EV- Cannes 2016. (May 17, 2016). [video zapis]. Dostupno preko: https://www.youtube.com/watch? $\mathrm{v}=$ Vrllwe7oLIw [20.4.2018]

Manro, A. (2015). Bekstvo. Preveo Predrag Šaponja. Zrenjanin, Novi Sad: Agora. May, Charles E. (ed.). (2013). Critical Insights: Alice Munro. Ipswich, Massachusetts: A Division of EBSCO Publishing.

Munro, A. (1968). The Peace of Utrecht. In Munro, A. (1968). Dance of the Happy Shades (p. 199). New York: McGraw-Hill. 
Munro, A. (2013). In Her Own Words: 2013 Nobel Prize Lecture in absentia [on-line]. Dostupno preko: https://www.nobelprize.org/uploads/2018/06/ munro-lecture.pdf [15.04.2019]

Ravitch, M. (2002). Fiction in Review. Yale Review, 90, 170. In Duncan, I. (2011). Alice Munro's Narrative Art (p. 161). New York: Palgrave Macmillan.

Romney, J. (Aug 7, 2016). Pedro Almodóvar: 'Nobody sings. There's no humour. I just wanted restraint.' The Guardian. Dostupno preko: https://www.theguardian.com/film/2016/aug/07/pedro-almodovar-observer-interview [26. 10. 2018]

Ruiz, E. (2005). Hispanic Culture and Relational Cultural Theory. Journal of Creativity in Mental Health, Vol.1 (1), 33 - 55.

Živković, D. (ur.). (1992). Rečnik književnih termina. Beograd: Nolit.

\title{
Tomislava T. Đorđević
}

\section{JULIET AND JULIETA - CANADIAN EXPERIENCE IN SPANISH CULTURAL CONTEXT}

\begin{abstract}
Summary
Although he encountered a seemingly insuperable obstacle in the form of cultural differences, Pedro Almodóvar eventually managed to complete his adaptation of Alice Munro's stories and named the film Julieta. First by juxtaposing the differences and then by seamlessly blending them together, Almodóvar creates a new image, providing an interesting insight into the world of the main character. Not only does he succeed in painting the subtlest nuances of the stories' characters and their relationships, but he also demonstrates an impressive capability of dealing with Munro's eternal mother-daughter tension by finally letting them finish their dialogue.
\end{abstract}

Key words: cultural differences, adaptation, mother-daughter tension, dialogue. 